\title{
Intergenerational Effects of Maternal Exposure to Drought in Utero on Newborn Size in Rural Malawi
}

\author{
Thokozani Hanjahanja-Phiri \\ School of Public Health and Health Systems, University of Waterloo, Waterloo, ON, Canada
}

\section{Dear Editors}

Previous studies have shown that maternal undernutrition during pregnancy is associated with altered fetal growth and neonatal outcomes. More recently, data from the Great Chinese Famine and the Dutch Famine studies have shown that the effects of exposure to famine in utero can spill over to subsequent generations. To further examine the potential intergenerational impacts of maternal drought exposure in utero, Hanjahanja-Phiri [1] took advantage of a natural experiment from 3 droughts (1981/82, 1987/88, and 1992/93) of varying severity in rural Malawi.

To derive maternal exposure to drought in utero during the first trimester and second-third trimesters, maternal date of birth were matched with the corresponding 3 drought years. Other data for outcomes and control variables were sourced from the International LipidBased Nutrient Supplements (iLiNS) DYAD-M randomized clinical trial including data for prenatal supplements of small quantity, lipid-based nutrient supplements (SQ-LNS), and iron-folic acid (IFA) [2]. Maternal residence in early life and place of birth were not recorded by the trial. Thus, the Hanjahanja-Phiri study used a proxy derived from the lan- guage spoken by the participants and if it matched the main regional language of the study population, Yao, the assumption was that they were born in the study area.

There were no significant first trimester effects on birth outcomes from maternal exposure to drought in utero, after controlling for covariates. However, maternal exposure to drought in the secondthird trimester compared to non-drought exposure in utero was significantly and positively associated with imputed birth weight $(88.497 \mathrm{~g}, \quad 95 \%$ CI [11.572:165.422]). Among infants of mothers exposed to drought in the first trimester, no significant effects on infant length-for-age $\mathrm{Z}$ score (LAZ) were observed for prenatal supplementation with SQ-LNS on infant LAZ compared to the IFA, controlling for covariates. However, prenatal supplementation with multiple micronutrients compared to IFA produced significant effects on infant LAZ (-0.853 SD, 95\% CI [-1.446:-0.259]).

An unexpected finding of the study was that maternal in utero exposure to drought during the second-third trimester was associated with an increase in infant LAZ, controlled for covariates. Even the study's sensitivity analyses, which removed the effect of maternal exposure to drought at age $0-5$ year in the control group, did not significantly alter the results. This outcome is different from the small number of studies that have previously looked at similar associations. For example, infants born to mothers with gestational exposure to the Dutch Famine were more likely to have decreased birth length but not reduced birth weight, compared to unexposed controls [3]. Maternal in utero exposure to the Great Chinese Famine was not only negatively and significantly associated with infant LAZ but also with infant weight-forage $\mathrm{Z}$ score [4]. However, the anthropometry measurements for the Great Chinese Famine study were taken between age 0 and 18 years, a range that extends beyond the scope of the Hanjahanja-Phiri study [4]. Although there were limitations to the data, (such as the absence of maternal place of birth and residence in early life, and missing date of births), these findings, nevertheless, add to the evidence supporting the intergenerational impacts of females being exposed to inadequate nutrition in utero, and suggest that further studies in regions with vulnerable populations are important.

\section{KARGER}

(c) 2018 S. Karger AG, Basel

E-Mail karger@karger.com

www.karger.com/anm
Thokozani E. Hanjahanja-Phiri, PhD

School of Public Health and Health Systems

University of Waterloo

Waterloo, ON N2L 3G1 (Canada)

E-Mail thokozani.phiri@gmail.com 


\section{References}

1 Hanjahanja-Phiri T: Intergenerational Effects of Maternal Exposure to Drought in Utero on Newborn Size: Evidence from a Retrospective Cohort Study in $\mathrm{Ma}-$ lawi. GCC Working Paper Series, GCC 18-01, 2018. https://repository.upenn.edu/ gcc_economic_returns/19/(accessed May 7, 2018).
2 Ashorn P, Alho L, Ashorn U, et al: The impact of lipid-based nutrient supplement provision to pregnant women on newborn size in rural Malawi: a randomized controlled trial. Am J Clin Nutr 2015;101:387397.

3 Painter RC, Osmond C, Gluckman P, Hanson M, Phillips DI, Roseboom TJ: Transgen- erational effects of prenatal exposure to the dutch famine on neonatal adiposity and health in later life. BJOG 2008;115:12431249.

4 Fung W, Ha W: Intergenerational effects of the 1959-61 China famine. Risk, Shocks, and Human Development. Palgrave Macmillan, London, 2010, pp 222-254. 